\title{
Effective Adaptation of Music Intervention in the Psychological Management of Late Life Depression in Nigerian Communities
}

\author{
Osimade Olabisi Modupe \\ Department of Guidance and Counselling, Faculty of Education, University of Ibadan, Ibadan, Nigeria
}

Email address:

osimadeolabisi@yahoo.com

\section{To cite this article:}

Osimade Olabisi Modupe. Effective Adaptation of Music Intervention in the Psychological Management of Late Life Depression in Nigerian Communities. Clinical Medicine Research. Vol. 9, No. 5, 2020, pp. 103-113. doi: 10.11648/j.cmr.20200905.12

Received: August 22, 2020; Accepted: September 1, 2020; Published: September 28, 2020

\begin{abstract}
Depressive symptoms in late life has been a global phenomenon affecting older adults mental health stability and general well-being. Studies on the psychological management of the disorder in Nigeria have variously adopted therapies that exerts cognitive, sensory and motor abilities of the elderly thereby generating very minimal results. The pre-test, post-test, control group quasi experimental design with a $3 \times 5 \times 3$ factorial matrix was adopted for the study. A total of sixty-four (64) participants were purposively selected from two randomly selected local government areas in Ibadan. Participants were further randomly assigned into an experimental group-Music Intervention Group (34) and the Control Group (30). Data was subjected to Analysis of covariance (ANCOVA). There was a significant main effect of treatment on late life depression ( $\mathrm{F}=17.554$, $\mathrm{p}<.05, \eta^{2}=.290$ ). Music Intervention ( $\left.\tilde{\mathrm{x}}=20.17\right)$ effectively managed late life depression vis-a-vis those in the control group $(\tilde{\mathrm{x}}=7.832)$. There was no significant main effect of personality traits and health locus of control on late life depression. The study ascertained the effective adaptation of music intervention in the psychological management of late life depression of community dwelling older adults, thereby adding to existing literature on music intervention for future research. This contribution is an advancement to late life depression study and management in Nigeria. Findings from the study can be adopted in both community and clinical studies of depression.
\end{abstract}

Keywords: Music Intervention, Health Locus of Control, Late Life Depression, Community Dwelling Older Adults

\section{Introduction}

Globally, late life depression (LLD) is a psychological phenomenon affecting older adults mental health stability and general well-being. At one time or the other, older adults aged 65 years and older have manifested symptoms of depression which is often missed for age related complaints [10] Old age is a phase of life with accompanying decline in health, physical and mental activities. Manifestations of depression at this stage is characterized by repeated feelings of worthless and guilt, hallucinations, loneliness causing a gradual or total withdrawal from activities once considered pleasurable. Approximately about 350 million people worldwide are said to have at one time or the other suffered depression [39] which was why is was projected to be the leading cause of burden of disease from 2020 onward. The growing population of older adult is estimated at 901 million to more than 1.4 billion within the spate of 15 years placing them at risk of diseases projected to be the cause of disability-adjusted life especially in low income countries [35] Averagely, older adults manifesting depressive symptoms are set to increase which could constitute a major social risk to the sufferer and the larger society.

Nigeria, like any other sub-Saharan African countries had witnessed rapid increase in the number of older adults which made up about $3.1 \%$ (i.e. about 5.9 million of their total population estimated at 191 million within a 5 -year period of 2012-2017 [25]. Averagely, the number of older adults manifesting depressive symptoms is set to increase proportionately within these periods, hence the need to explore different management options for the ravaging disorder. LLD refers to manifestation of a depressive episode for the first time in older adults aged sixty-five years and above characteristics of which include hallucination, loss of 
interest in once pleasurable activities and dysphoria [7]. Depressed older adults often exhibit considerable loss of selfesteem, they constantly ruminate over past mistakes or failures. Changes may be observed in their eating and dietary pattern resulting from constant aversion to food, loss of appetite which could ultimately result in rapid weight loss.

Studies on late life depression and management in Nigeria many of which focused on prevalence, risk factors and pharmacological interventions had expressed serious public health concern on consequences of untreated LLD on the individual, the family and the society as a whole $[15,20]$. Consequences which include and not limited to habitual sleeplessness (insomnia), schizophrenia, delusion and sometimes thoughts of death or suicide. Nigerian Demographic Health Survey [26], approximated that sixty four percent of the Nigerian population of which $40.2 \%$ are older adults live in communities, and only thirty six percent in urban cities. Community dwelling older adults are fast becoming isolated [32] and Nigeria is currently experiencing a larger influx of older adults in communities than in urban areas primarily as a result of the increased rate in rural-urban movements by the younger populations [4]. This movement had facilitated alarming increase in the total number of older adults' resident in communities. A large number of Nigerian communities' lack basic infrastructural facilities capable of meeting the health needs of the elderly population. Portable drinking water, health and wellness awareness, good road network that could facilitate transportation to urban cities for medical checkups and the characteristic poverty levels of community dwellers are some of the odds against the effective geriatric health care in these communities [4].

Despite challenges in health care delivery observed in many Nigerian communities, diagnosis and management of depressive symptoms in late life is reported to have been further complicated by the environment, individual beliefs, differences in depression outlook, mental awareness, accessibility to healthcare etc., all of which are limiting factors for most communities in developing countries like Nigeria [20,34]. Unfortunately, there has been paucity of research on factors associated with the development of depressive disorder part of which forms the moderating variables for this study in Nigeria. There are clear evidences that older adults are assailable to almost all of the risk factors of depression as much as the younger population. Older adults are variously exposed to other factors not peculiar to the young populace. Blazer and Hybels [5] classified these factors into three categories: the biological/hereditary factors; the psychological factors and the social/environmental factors.

Personality trait is one of the psychological risk factors of LLD capable of interfering with the individual's intrinsic attribute determining their extrinsic dispositions towards health and eventual culpability to geriatric depression. For instance, the ability of an older adult to adjust to a stressful life event like widowhood or bereavement and their attitude towards stress is determined by their personality trait [5]. Mental health challenge like depression causing reduced abilities to perform daily tasks whose rate of recovery is strongly hinged on personal outlook to health and medical regimen can be proportionately managed depending on the personality trait inherent in the individual and his attitude towards help.

Risk factors of depression observed either by the individual or a close relative according to Costa [9] can be indicated by the degree of apprehension, resentment, timidity, impertinence and culpability exhibited by the individual. Older adult's personality trait is a significant factor on their health locus of control (i.e. their ability to take health decisions). Richard, Jenkins and Thomas [29], confirmed that older adult's health decisions on mental health issues like depression is hinged on their personal conviction that the outcome of their health decision is determined by three factors: their innate will to get well (Internal HLOC), their doctors/psychiatrists diagnosis and prescriptions (Powerful Others HLOC) and on fate/luck (Chance HLOC).

In most Nigerian cultures, it is assumed that close relations like family members related to depressed older adult take up the social responsibility of taking health decisions on their behalf. Their contentment of the decisions taken by these close relatives invariably supersedes their thoughts. In some tribes in Nigeria, older adult's trust and reliance on spiritual or supernatural phenomenon strongly dictate their control beliefs. Community dwelling older adults in Nigeria are distinctly different in their exhibition of a great tenacity to accept that their health outcomes are supernaturally related to chance, fate, luck or special deserving favours from ancestors or the spiritual realm $[30,11]$.

Health locus of control for most community dwelling older adults in Nigeria is expressed in their psychopathological views and outlook to mental health and mental health services delivered through alternative means such as religious organizations, immersion in exorcism, attending deliverance sessions, prayer and fasting, time travelling in trance and visions, traditional healers use of incisions, herbal mixtures etc. The general assumption was that traditional believers could easily diagnose physical complaints of severe depression and profess influencing beliefs in supernatural alliances as the cause of the disorder. There is a constant basis for disagreement between mental health providers, medical personnel and psychotherapists alike on the construction of experience of depression by traditional African older adults. This is particularly relevant in Nigeria especially in communities surrounded with diverse cultural and traditional assertions affirming the former belief in herbal therapies and concussion, as an effective choice of management for mental health conditions that seems to defy medical understanding [3]. The good news however is that, LLD can be effectively managed in and out of a clinical environment with psychotherapies, pharmacotherapies, electroconvulsive therapy (ECT) $[14,36]$. In view of these challenges, limitations in accessing mental health care for disadvantaged communities, literacy level and financial status of an average community dwelling older adults in Nigeria, this study is designed to examine the effective 
adaptation of music intervention in the psychological management LLD in community dwelling older adults.

\section{Music Intervention}

Psychotherapeutic interventions, the talking treatment as it is referred to in some climes, is the process of engaging in an in-depth discussion (sessions) with a patient referred to as client to obtain facts and information regarding his current emotional state. Studies on depression in both young and older populations have established the effectiveness of these interventions as a treatment regimen. Its efficacy in resolving psychological disorders have established its empirical relevance across cultures [3, 14, 36, 37]. Music intervention is an 'admixture' of two words, 'music' and 'intervention' which requires different interpretations for proper understanding. Aluede [3] investigated music especially in African traditional societies as one of the craftiness concerned with combining rhythms with an aesthetical imagination of thoughts, feelings and expressions.

Music intervention involves the skills and expertise of applying musical sounds in strengthening and rejuvenating a relatively poor state of health. One of the reasons for using music as an intervention in most domains of health is the fact that it is alluring to people of different ages and cultures. Music creates an avenue for the exploration of innovative ideas and issues in dealing with aging issues. It is a natural avenue for older adults to relieve past experiences and ruminate over them. Involvement in musical activities for older adults comes with numerous health benefits. Older adult's participation in musical activities helps in sustaining their sense of imagination and achievement, regardless of obvious disadvantages. When music is quietly listened to, the listener is naturally relaxed with clear imagination, mood elevation and soul lifting [6].

The management of depressive symptoms with medications is often dynamic, but reactions, contraindications and dosage control peculiar to certain conditions abound for older adults [33]. Psychotherapies employed on short term basis have equally been adopted with huge success rate on depressed older adults. These established methods are appropriate with the older population when and where access to treatment with a trained psychotherapist are available. However, older adults who are incapacitated, environmentally limited or financially handicapped may not have access to such services and hence opt for other management alternatives or totally ignore the symptoms. Music interventions has been largely adopted for use with depressed older adults in old people's home, healing homes, deliverance sessions, adult day care, and old people's health care centers. In an attempt to sustain functionality for depressed older adults, evolving interventions and strategies are continuously experimented to address depression in late life in their various environment considered to be their comfort zones in hopes of preventing more serious co morbid medical issues. The quest for an optimized and accessible psycho-educational strategy has invented the exploration of a therapeutic intervention in music.
The development of a strategic management of late life depression requires that the symptoms and behavioral manifestations associated with diagnosis be taken into consideration. These may include a sad disposition; worthlessness; guilt feelings and dissatisfaction; poor selfesteem; indecision; somatic complaints; amnesia; and even suicidal ideation. Foundations of the use of music intervention with depressed older adults population is found in the ideation that listening to music is a redirected strategy that explains the process of channeling negative energy towards meditation which is found as a component of music. Music is necessary in initiating a work through of challenges found in its ability to relax and prepare the mind and brain for crystal thinking. Similarly, music has been established as an effective means of reducing stress [18]. Thus, music intervention is found to be constructively effective for the psychological management of late life depression especially in individuals whose depressive symptoms is preceded by anxiety and agitation [27].

\subsection{Features of Music Therapy}

\subsubsection{Patient's Health History}

This is considered in determining appropriate music for a music therapy session, the knowledge and familiarity of the client's medical history is a key factor. The tenacity of the depressive symptoms and the presenting symptoms are equally of particular interest. Initial coping mechanisms obtained from the patient/client, careful analysis of the environmental stressors and precipitants for depression are factors needed to be considered before the commencement of treatment. In addition, the auditory ability of the client as well as the ability to interprete musical messages are also needed entry skills in music intervention for older adults. One major technique of music therapy is the ability to maintain a continuous muscle assuagement, which may be counteractive in the geriatric population with cases of arthritis or osteoporosis [18]. Music usage as a catalyst for tutored visual projection is not considered suitable for the geriatric population limited by chronic cognitive impairment or physical presentations of psychosis. Evidences abound of the dynamism involved by musicians which is noncomparable with non-musicians, music interventions performed by non-skilled professional might result in differential reflexes.

\subsubsection{Previous Music Experience}

Older adult's musical preferences and interest is another strong factor in determining the success or otherwise of music interventions with the geriatric population. It is important to engage the patient on his music preferences and interests. Old age is a phase of life where priorities are not given to social acceptability of a need but to the health implications of such needs. It is of great importance for the therapist to confirm the degree to which music listening forms part of the client's daily activities. Questions like what informs the need to listen to music, times they considered music listening necessary, genres of music they considered 
fascinating etc., should form the basis of entry behaviours into music intervention sessions. Other questions may be directly related to the treatment planning and execution. Questions relating to the events preceding a depressive mood, timing of depressive symptom manifestations etc., might just be necessary. The idea of inviting friends or family members who the client considered a 'social ally' might not be bad entirely, social connectedness enhances the social function of music listening.

\subsubsection{Physical Symptoms}

Having highlighted the client's health records, musical preferences, physical symptoms presented with depressive disorder, it becomes necessary to establish presenting problems. As typical with old age, older adult expression of depression might not be clear or distinct as lots of attributions and self believes might complicate reports. Every complaint needed to be carefully considered while addressing the causes and consequences of depression. Most importantly, general complaints that could be resolved during therapy are noted alongside individual functioning ability to ascertain their optimal rate of manipulation. For instance, music is a known sleep stimulant capable of eliciting a refreshed energy if well inculcated into daily living. During a depressive episode, characterized by negative thoughts, music listening can help in ruminating and analyzing situations objectively and indirectly revert the mood.

\subsubsection{Goal Setting}

The function of music in managing depressive symptoms in late life is explicitly presented to the participants before the commencement of the sessions. Quite often, certain challenges are resolvable by a continuous music-listening habit that if maintained can be a healthy distraction from personal conflicts and negative thoughts. It can facilitate a relaxed disposition not compliant with stress, and sleep stimulation. Goal setting follows immediately after diagnosing presenting symptoms.

\subsubsection{Music Selection}

During interviews, information eliciting music preferences are obtained from the participants. However, only articulated observation of the client during music listening will dictate the extent to which emotions is attached to the music. Observations of agitation, thought expressions and general body reactions to the sound of music will indicate the efficacy of the choice of music selected. On the other hand, psychic arousal may be the outcome of a strong, emotional dispositions towards the music [18]. Familiar music is tested first, while the therapists closely record the observations. The therapist may then select music with a significant record of success rate.

\subsubsection{Pretest}

In evaluating the effectiveness of music intervention, there is need to ascertain entry behavioural characteristics. Obvious symptoms are accessed with the use of standardized instruments. Assessment tools devised to suit the older adult's population include Geriatric Depression Scale (GDS), Brief Symptom Inventory (BSI), Self-Esteem Inventory (SEI) and Beck Depression Inventory (BDI).

\subsection{Techniques of Music Therapy}

Music intervention is a psychotherapeutic process that allows for expressions of varying techniques including both creative and receptive. Older adults with physical and mental health issues might not be too expressive about their challenges and its accompanying pains. Ageing is a process that individuals finds stressful, a lot of activities exerts the abilities of older adults to function effectively. In situations like this, they often need receptive therapies that is soothing. The act of leisure music listening is meant to translate the individual into a relaxed state that seems meaningful. Gaines [42] listed some techniques needed for effective inculcation of music into therapy:

1) Introduction of Creative and or expressive music: For older adults, inculcation of creative relatable music creates avenue for social expression as it elicits a response and bring back memories.

2) Improvisation: In a music intervention session with older adults, music may be improvised to call on their cognitive abilities to relate to music they have heard before.

3) Song Writing: Song writing in music therapy techniques allows the therapist the creative ability to draw-up music to suit the client's need. In a population of older adults participants, the therapist might need to modify available music to suit their physical and mental capability

4) Drumming: Drumming is an activity that encourages the use of the psychomotor ability to the participants in session. Participants are allowed to play together with or without accompanying song. Drum beating creates an avenue to socially interact as a means of relieving emotions in depressed individuals.

5) Music Performance: This technique was adopted in this study. Music performers were invited to play their music while participants danced along with the rthymn. This therapist may encourage participants to invite one or two family members into the session to make the environment relatable.

6) Lyric Discussion: The therapist might encourage participants to discuss lyrics in order to help identify problems. Older adults are quick to respond to familiar music, they tend to discuss music especially when they are in the company of their fellow seniors.

7) Music and Imagery: Designed to replace cognitive dysfunctions and other thought dysfunctions identified with depression. The technique requires that the client transcends to his subconscious and create an image of where he would love to be, it is an unconscious reminiscence of a state of calmness and peaceful imagery.

8) Special picture placement of the cause of depression: This technique referred to as 'trance' in some quarters 
is a careful administration of music with long rhythmic phrases into the subconscious mind of the client allowing to client attain a state of calmness leading to a deep sleep or a long nap. Alternatively, in this state, the client is allowed to picture themselves involved in activities they thought they could not do.

9) Using music to generate mental images through guided affective imagery: This technique involves inculcating other musical creativities relating to art and dance, dance-drama, cultural displays, worships into therapies. These modes are considered quite relatable as older adults can identify with the source of music and it requires less exertion or manipulation. The technique allows for active participation of both the client and the therapist, thereby increasing social relationship.

10)Gentle listening therapeutic exercises, facial massage of the mimetic muscles, combination of the mimetic muscle relaxation with music listening and sleep exertion. In using music to generate mental images through guided affective imagery designed to replace cognitive dysfunctions and other thought dysfunctions identified with depression; the technique requires that the client transcends to his subconscious and create an image of where he would love to be, it is an unconscious reminiscence of a state of calmness and peaceful imagery. Special picture placement of the cause of depression is another technique referred to as 'trance' in some quarters. It is a careful administration of music with long rhythmic phrases into the subconscious mind of the client allowing the client attain a state of calmness leading to a deep sleep or a long nap. Alternatively, in this state, the client is allowed to picture themselves involved in activities they thought they could not do. This technique involves inculcating other musical creativities relating to art and dance, dance-drama, cultural displays, worships into therapies. These modes are considered quite relatable as older adults can identify with the source of music and it requires less exertion or manipulation. The technique allows for active participation of both the client and the therapist, thereby increasing social relationship.

\section{Hypotheses}

$\mathrm{H}_{\mathrm{O}} 1$-There will be no significant main effect of treatment on late life depression.

$\mathrm{H}_{\mathrm{O}}$ 2-There will be no significant main effect of health locus of control on late life depression.

$\mathrm{H}_{\mathrm{O}} 3$-There will be no significant main effect of personality trait on late life depression.

Method

\subsection{Ethical Approval}

Administrative permission to conduct the research was given by the University of Ibadan Institutional Ethical Review Board (UI/UCH IRB). Letter of introduction obtained from Department of Guidance and Counselling, University of Ibadan was taken to the Ministry of Health at the state local government secretariat, Agodi, Ibadan. The approval to conduct the study was taken to the Primary Health Care Department of each local government selected for further approval.

\subsection{Participants}

The locale of the study was Oyo State, Southwest Nigeria. Two rural communities in two local government areas (LGAs) within Oyo State were purposively selected for the study. Sixty-four participants screened with the Geriatric Depression Scale (GDS-Short Version) were randomly assigned into Music Intervention Group (34) and the Control Group (30). Treatment lasted eight weeks. Simple random sampling technique was used in selecting rural communities within the local governments selected.

\subsection{Study Design}

The study adopted a pretest-posttest, control group quasiexperimental design. One experimental group was exposed to Music intervention, the Control group was exposed to teachings on 'Safety Measures in Old Age'. The two groups were crossed with personality trait at five levels (extraversion, agreeableness, openness, neuroticism and conscientiousness) and health locus of control at three levels (internal, powerful others and chance health locus of control). Instrumentation

Four instruments translated into the local language were used to collect data for this study: Hamilton Rating Scale for Depression (HAM-D); The Big Five Personality Inventory; Multidimensional Health Locus of Control Scale and the Geriatric Depression Scale (Screening Instrument). The instruments were translated into Yoruba language at the Department of Linguistics and African Languages, University of Ibadan bearing in mind the literacy level of participants in other to ensure adequate understanding and comprehensibility of constructs each instrument is set to measure. No Yoruba version of the instruments was known to have been in existence prior to the time of this study. The validity of the instruments was determined through a pilot study conducted two weeks peceeding the commencement of the study.

Hamilton Rating Scale for Depression (HAM-D)

This is an assessment scale designed specifically for older adults to assess indication of depression. Max Hamilton originally published the scale in 1960 and revised it in 1966 and 1967 [16]. The instrument is used to access the severity of geriatric depression by investigating emotions, contrition, suicide ideation, restlessness, anger or retardation, anxiety, weight loss, and somatic symptoms. The original 1960 version contains 17 items to be rated (HRSD-17), but four other questions are not added to the total score and are used to provide additional clinical information. Each item on the questionnaire is scored on a 3-5 point, depending on the item, and the total score is compared to the corresponding descriptor. Assessment time is estimated at 20 minutes. A score of $0-7$ is considered normal. Scores of 20 or higher 
indicate moderate, severe, or very severe depression, and are usually required for entry into a clinical trial.

\section{The Big Five Inventory BFI Questionnaire}

This is a standardized psychological assessment instrument developed by John, Donahue and Kentle [21]. The instrument contains 44 items designed to measure personality from a five-dimension perspective (Extraversion, Agreeableness, Conscientiousness, Introversion and Openness to Experience). Direct scoring is used for all the items. It is scored on a 5-point scale ranging from 1-5, 1 -Disagree Strongly, 2-Disagree a little, 3-Neither agree nor disagree, 4Agree a little and 5-Agree Strongly. Values of the numbers shaded are added to obtain the respondent's scores in each of the subscales. The coefficients of reliability provided by John et al [21] are Cronbach alpha.80-and two-weeks test-retest of.76. Big Five inventory has mean convergent validity coefficient of.75 and.85 with the Big Five instrument authored by Costa and McCrea (43) and Goldberg (44) respectively.

\section{Multidimensional Health Locus of Control Scale}

Health locus of control scale (HLCS) was developed by Crown and Marlowe [45] and was revised by Wallston, Wallston, Kaplan and Maides [38]. It assesses the extent of control a person thinks he/she has over own state of health. The health locus of control scale contains eleven (11) items that are scored on a 6-point likert ranging from 1 (strongly disagree) to 6 (strongly agree). Five (5) items $(1,2,8,10,11)$ are worded in internal direction to determine internal health locus of control and are directly score while Six (6) Items (3, $4,5,6,7,9)$ are worded in the chance health locus of control and $(5)$ items $(12,13,14,15,16)$ are worded in the powerful others health locus of control with both chance and powerful others control scored directly, determining the external health locus of control. Sample items are "If I take care of myself, I can avoid illness.", "Good health is largely a matter of good fortune." The Health Locus of Control scale has shown to have a good reliability and validity properties. Wallston and colleague (38) reported test-retest reliability co-efficient of.71 in a study involving a sample of women who were involved in weight reduction programme. Salami [31] as cited in Akomolafe and Popoola [2] reported test-retest reliability coefficient of.75 using Nigerian Students, a two week the pilot test with the geriatric population however recorded a reliability coefficient of.76

Geriatric Depression Scale-Short Form (GDS 15)

The GDS [40] is a yes or no questionnaire that focuses on assessing depression in older adults. The original version has 30 questions and has been determined valid and reliable [40]. There have been validation and reliability studies conducted on acutely ill older adults using the GDS15, GDSIO and GDS4 which are fifteen, ten and four-item scales respectively. Of these shortened versions, the GDS15 has been cited both as valid and as reliable with respect to older adults in general practice with a high correlation of $r=.89$ to the GDS-Long Form. The GDS 15 will be used in this study because of the population and the number of instruments that they will have to complete. The overall purpose of this measure is to determine if the participants meet the criteria for major depressive disorder.

\section{Procedure}

The study was carried out in four phases: pre-sessional activities, pre-test, treatment and post-test. At the presessional phase, participants were contacted through their community heads and religious organizations. They were thereafter visited in their homes to obtain their consent to participate in the study. Time and venue were further allotted to participants and their carerers for the screening. Participants were screened at the pretest phase using the Geriatric Depression Scale at this stage and allocated into the music intervention group and the control group respectively using the balloting process. At the treatment phase, participants were exposed to eight weeks (eight sessions) of treatment. Each session lasted forty-five minutes; though the participants in the control group were not treated, they were given a health talk titled: "Safety Measures in Old Age". The goals of the treatment at the music intervention group was achieved by the introduction of relatable musical choices. Participants were asked to indicate five music performances of their choice at the second session. These musical records were played at intervals during and after each session. Participants were requested to invite family members into the sessions to make the atmosphere relatable. The musicians invited were given tokens in appreciation of their support and services. At the final phase (post-test phase), the Hamilton Rating Scale for Depression was administered to the participants in the experimental group and the control group to obtain the treatment outcome results (posttest scores).

\section{Results}

Data collected were analyzed using the Analysis of covariance, and the Scheffe Post-hoc analysis at 0.05 level of significance. ANCOVA was also used to determine the main effects and interactive effects of the independent and moderating variables on the dependent variable (geriatric depression). The Scheffe Post-hoc Analysis was used to determine the direction of differences for significant results.

Table 1. Demographic Profiles of Respondents.

\begin{tabular}{lll}
\hline Profile of the respondents & Frequency & Percentage \\
\hline Age & & \\
65-70 years & 31 & 46.3 \\
$71-75$ years & 13 & 19.4 \\
$76-80$ years & 13 & 19.4 \\
$81-85$ years & 9 & 13.4 \\
$86-90$ years & 1 & 1.5 \\
\hline
\end{tabular}




\begin{tabular}{|c|c|c|}
\hline Profile of the respondents & Frequency & Percentage \\
\hline \multicolumn{3}{|l|}{ Gender } \\
\hline Male & 31 & 46.3 \\
\hline Female & 36 & 53.7 \\
\hline \multicolumn{3}{|l|}{ Religion } \\
\hline Christian & 40 & 59.7 \\
\hline Muslim & 24 & 35.8 \\
\hline Others & 3 & 4.5 \\
\hline \multicolumn{3}{|l|}{ Ethnicity } \\
\hline Yoruba & 57 & 85.1 \\
\hline Igbo & 3 & 4.5 \\
\hline Others & 7 & 10.4 \\
\hline \multicolumn{3}{|l|}{ Marital status } \\
\hline Married & 55 & 82.1 \\
\hline Divorced & 12 & 17.9 \\
\hline \multicolumn{3}{|l|}{ Family type } \\
\hline Monogamous & 25 & 37.3 \\
\hline Polygamous & 42 & 62.7 \\
\hline \multicolumn{3}{|l|}{ Occupation (Past) } \\
\hline Farmer & 7 & 10.4 \\
\hline Trader & 22 & 32.8 \\
\hline Civil servant & 34 & 50.7 \\
\hline Engineer & 2 & 3.0 \\
\hline Musician & 1 & 1.5 \\
\hline Artisan & 1 & 1.5 \\
\hline \multicolumn{3}{|l|}{ Occupation (Present) } \\
\hline Retired/Pensioner & 39 & 58.2 \\
\hline Farming & 2 & 3.0 \\
\hline Trading & 9 & 13.0 \\
\hline Civil servant & 16 & 23.9 \\
\hline Clergy & 1 & 1.5 \\
\hline \multicolumn{3}{|l|}{ Living arrangement } \\
\hline With immediate family & 43 & 64.2 \\
\hline With relatives & 19 & 28.4 \\
\hline Alone with maids & 5 & 7.5 \\
\hline \multicolumn{3}{|l|}{ Significant negative event } \\
\hline Bereavement & 32 & 47.8 \\
\hline Sickness & 12 & 17.9 \\
\hline Finance & 6 & 9.0 \\
\hline Separation & 3 & 4.5 \\
\hline Non/Others & 14 & 20.9 \\
\hline
\end{tabular}

Hypotheses One: There will be no significant main effect of treatment on late life depression.

Table 2. Presents the summary of Summary of ANCOVA showing the main interactive effect of Treatment, Personality Traits and Health Locus of Control on Late life Depression ANCOVA showing the main interactive effect of Treatment, Personality Traits and Health Locus of Control on Late Life Depression.

\begin{tabular}{|c|c|c|c|c|c|c|}
\hline Source & Sum of Squares & DF & Mean Square & $\mathbf{F}$ & Sig. & Eta. Sq \\
\hline Corrected Model & $5504.582^{\mathrm{a}}$ & 23 & 239.330 & 6.661 & .000 & .781 \\
\hline Pretest Depression & 317.524 & 1 & 317.524 & 8.838 & .005 & .170 \\
\hline Main effect: & & & & & & \\
\hline Treatment & 630.655 & 1 & 630.655 & 17.554 & .000 & 290 \\
\hline Health Locus of Control & 217.372 & 2 & 108.686 & 3.025 & .059 & .123 \\
\hline $\begin{array}{l}\text { Personality Traits } \\
\text { 2-way Interactions: }\end{array}$ & 166.641 & 4 & 41.660 & 1.160 & .342 & .097 \\
\hline Treatment x HLOC & 112.184 & 2 & 56.092 & 1.561 & .222 & .068 \\
\hline Treatment x Personality Traits & 338.595 & 4 & 84.649 & 2.356 & .069 & .180 \\
\hline $\begin{array}{l}\text { HLOC x Personality Traits } \\
\text { 3-way interactions: }\end{array}$ & 555.762 & 6 & 92.627 & 2.578 & .032 & .265 \\
\hline Treatment x HLOC x Personality & 89.363 & 3 & 29.788 & .829 & .485 & .055 \\
\hline Error & 1544.881 & 43 & 35.927 & & & \\
\hline Corrected Total & 7049.463 & 66 & & & & \\
\hline
\end{tabular}

R Squared $=.781$ (Adjusted R Squared=.664)

The table shows the main interactive effect of Treatment, Personality Traits and Health Locus of Control. It is observed that there was a variance of 78.1 percent accounted for by the independent variables. It shows that there was a significant main effect of treatment on late life depression of community dwelling older adults. $\left(F=17.554, p<.05, \eta^{2}=.290\right)$. The 
hypothesis is therefore rejected.

Table 3. Estimated marginal means of Treatment on Geriatric depression of rural community dwellers.

\begin{tabular}{lllll}
\hline \multirow{2}{*}{ Treatment Groups } & $\overline{\mathbf{x}}$ & $\begin{array}{l}\text { Std. } \\
\text { Error }\end{array}$ & \multicolumn{2}{c}{$\mathbf{9 5 \% \text { Confidence Interval }}$} \\
\cline { 4 - 5 } & & Lower Bound & Upper Bound \\
\hline Music intervention & 20.17 & 1.259 & 17.636 & 22.713 \\
Control & 7.832 & 1.298 & 5.214 & 10.450 \\
\hline
\end{tabular}

Table 2 shows the estimated marginal means of Treatment on Geriatric depression of rural community dwellers.

Hypothesis two: There will be no significant main effect of Health Locus of Control on late life depression.

Table 4. Estimated marginal means of Health Locus of Control on Geriatric depression of rural community dwellers.

\begin{tabular}{|c|c|c|c|c|}
\hline \multirow{2}{*}{$\begin{array}{l}\text { Health Locus of } \\
\text { Control }\end{array}$} & \multirow{2}{*}{$\overline{\mathbf{x}}$} & \multirow{2}{*}{$\begin{array}{l}\text { Std. } \\
\text { Error }\end{array}$} & \multicolumn{2}{|c|}{ 95\% Confidence Interval } \\
\hline & & & Lower Bound & Upper Bound \\
\hline Chance & 6.940 & 2.869 & 1.154 & 12.726 \\
\hline Powerful Others & 13.841 & 1.385 & 11.049 & 16.634 \\
\hline Internal & 15.123 & 1.169 & 12.765 & 17.481 \\
\hline
\end{tabular}

Table 3 showed the estimated marginal means of Health Locus of Control on late life depression. The result showed that there was no significant main effect of Health Locus of Control on Geriatric depression of rural community dwellers. $\left(\mathrm{F}=3.025, \mathrm{p}>.05, \eta^{2}=.123\right)$. The hypothesis is accepted.

Hypothesis three: There will be no significant main effect of Personality trait on late life depression.

Table 5. Estimated marginal means of Personality Trait on late life depression of rural community dwellers.

\begin{tabular}{lllll}
\hline \multirow{2}{*}{ Personality Type } & $\overline{\mathbf{X}}$ & Std. & \multicolumn{2}{l}{$\mathbf{9 5 \%}$ Confidence Interval } \\
\cline { 5 - 5 } & & Error & Lower Bound & Upper Bound \\
\hline Extraversion & 9.991 & 2.016 & 5.924 & 14.057 \\
Agreeableness & 16.016 & 1.675 & 12.637 & 19.395 \\
Openness & 11.843 & 2.136 & 7.535 & 16.151 \\
Neuroticism & 14.571 & 1.615 & 11.315 & 17.827 \\
Conscientiousness & 14.301 & 2.652 & 8.953 & 19.648 \\
\hline
\end{tabular}

Table 4 showed the estimated marginal means of Personality traits on late life depression of community dwelling older adults. Result indicated that here was no significant main effect of Personality trait on late life depression of community dwelling older adults. $(F=1.160$, $\mathrm{p}>.05, \eta^{2}=.097$. The hypothesis is accepted.

\section{Discussion}

The first hypothesis stated that there will be no significant main effect of treatment on late life depression of community dwelling older adults. This hypothesis was rejected as the result in table 1 confirmed that the main effect of treatment on geriatric depression of rural community dwellers was significant. This connotes that music intervention was effective in the psychological management of late life depression fostering a significant reduction effect. The mean score of participants in music therapy group $(\tilde{x}=20.17)$ showed they benefitted immensely during the sessions in comparison to the mean outcome of $(\tilde{\mathrm{x}}=7.832)$ in the control group. This finding corroborates the conclusions of Cevasco, Kennedy and Generally [6], Chan, Mok and Tse [8] and Han, Kwan, Chen, Yusof, Chonh, Goh and Yap [17] suggesting that music therapy was effective leading to health promotion and happiness amongst the geriatric population.

Lai and Good [22], in their study of the role of music in improving quality of sleep in older adults highlighted physiologic effects of music as a coping mechanism for sleep quality of depressed older adults. Their study reported the potency of music intervention in enhancing the general health and well-being of older adults. In contrast to their submission however, the quasi-experimental study of Madineh, Sanaz and Roghaieh [23], on the effects of Music Therapy on Anxiety and Depression in patients living with cancer recorded variabilities in the influence of music on depression and age of the participants. In other words, they stated that participants aged 30-45 living with cancer had a reduced depression after treatment in comparison to participants aged 65 and over.

A review of studies assessing the influence of preferred music on attitudes of older adults afflicted with dementia written between 1993-2005 also affirmed to the positive influence of music on the reduction of agitated behaviours in demented older adults with dementia. Although both studies adopted a relatively low sample size of 30 participants within the age bracket, they both took into consideration the musical preference of participants and encouraged family participation and intervention which was partly adopted in this study.

Hypothesis two stated that there will be no significant main effect of health locus on control on late life depression. The hypothesis was accepted because the result shown in table 3 indicated that there is no significant main effect of health locus of control (HLoC) on late life depression. Zimmerman [41] posited that the level of rurality in and of itself was not significantly associated with depression severity, prevalence rate, or incidence of depression other than healthcare utilization. The study concluded that although rural or urban status did not directly affect HLoC and depressive symptoms, she suggested follow-up analysis that indicated the possibility due to the heterogeneity of individuals within the communities and urban cities. The finding is in contrast with Aflakseir and Abadi's [1] study where relationship was established between the components of health locus of control with depression in older adults aged 65 and over. Although their result established the correlation of chance and powerful others health locus of control with depression; it reported lower levels of HLoC amongst individuals aged $65-74$ representing $60 \%$ of the total population used in the study.

This study established that the low internally perceived HLoC of older adults can strongly precipitate depression as health decisions for the geriatric population are either determined by their children, carerers or their social support circle. Older adults with low internally perceived HLoC felt that they are unable to adequately provide the financial means of obtaining healthcare either from the medical 
facilities available or seek the conventional means. Older adults who perceived more control on their physical and mental condition were less susceptible to depression.

Moreover, findings from this study suggested that attributing difficult conditions such as physical illness to God and destiny helped rural community dwelling older adults in Oyo state attain a better health. The stronger the older adult's HLoC, the stronger the health goals they anticipate for their wellness and the stronger their adherence to engage in health befitting behaviours even in the face of hardship and lack [41]. A vast body of evidence reveals that older adult's health beliefs and their ability to take healthy decisions on their wellness and health-related behaviour play a unique important role in their overall health status and general functioning. The firmer the inculcated belief control on their health, the higher their possibility of enlisting and sustaining efforts needed to adopt and maintain a positive healthseeking behaviour such as reporting in a nearby health centres when need be and checking with their doctors regularly for medical checkups.

The third hypothesis established that personality trait on late life depression was not significant. The personality traits explored in this study are the personality traits of the big five i.e extraversion, agreeableness, openness, neuroticism and conscientiousness. This implies that personality trait is not an important predictor for the onset of depression even in old age, and it is not in any way influenced by other predictors or aging factors. Other studies: Fanous and Gardner [13] found a strong direct role of extraversion, introversion and conscientiousness strongly predicting depression in younger populations. Just as Heady and Wearing [19] also reported that after analyzing the Big-Five traits, extraversion and introversion were the most potent predictor of late life depression. This study recorded the highest mean value for openness, agreeableness and neuroticism as closely linked to the complications of depression in old age which is highly related to the findings of Morse and Lynch [24] who reported that about $34 \%$ of the variance in subjective well-being of older adults was accounted for by agreeableness while about $1 \%$ was accounted for by extraversion. This result was at variance with other studies such as Evans and Cox [12] who found that Openness to experience significantly and positively predicted geriatric depression. The emergence of neuroticism as the strongest personality trait found to be more susceptible to geriatric depression was not per chance; neurotic personalities have characteristics that exhibit the act of getting themselves into situation that promote negativism and experience negativities [19], and give unique importance to negative reactions. Older adults who have exhibit traits of neuroticism show vulnerabilities in facing frustrations when pressured, hence culminating into depression, especially when resident in rural communities' void of social amenities.

\section{Conclusion and Limitations}

There are few limitations in the course of the study that are worthy of note. The sample size adopted in the study may not portray a true representation of older adults in communities in Oyo State. There is therefore a need for caution in the use of the findings of the study in a larger population. The inability of the researcher to control participants recruited for the study is another important limitation. Older adults lacking social support in terms of mobility and financial assistance could not make it to the study venue thereby increasing attrition rate recorded during the study. Regardless of these limitations, the findings of this study however, produced the following conclusions: Music intervention was effective in managing late life depression among community dwelling older adults. Personality trait and health control of control did not moderate the effect of treatment of geriatric depression of rural community dwellers.

\section{Acknowledgements}

The author wishes to thank the University of Ibadan for giving the ethical approval for the study, lecturers who are part of this study directly and indirectly, the participants for their time and efforts and the community heads at each local government authority.

\section{References}

[1] A. Afflakseir, and M. Abadi. The role of Health Locus of Control in Predicting Depressive Symptoms in a sample of Iranian Older Adults with Chronic Diseases. Iranian Journal of Psychiatry. 2016. 11: 2: 82-86.

[2] M. J. Akomolafe, and O. G. Popoola. Emotional Intelligence and Locus of Control as Predictors of Burnout among Secondary School Teachers in Ondo State, Nigerian European Journal of Social Sciences, 2011. 20, (3), 369-378.

[3] C. O. Aluede. Music Therapy in Traditional African Societies. Origin, basis and Application in Nigeria. Journal of Human, Ecol, 200620 (1): 31-35.

[4] O. Amoran, T. Lawoyin, and V. Laosebikan. The Prevalence of Depression among adults in Oyo State, Nigeria: A Comparative Study of Rural and Urban Communities. Australian Journal of Rural Health. 2007. Vol. 15 (3). 211215; doi: 10.1111/j.1440-2006.00794.

[5] D. Blazer and C. Hybels. Origins of Depression in Later Life, Journal of Psychological Medicine, 2005. Vol. 35, 1-12; doi: $10.1017 / \mathrm{S} 0033291705004411$

[6] A. M Cevasco, R. Kennedy and N. R. Generally, N. R. Comparison of Movement-to-Music, Rhythm Activities, and Competitive Games on Depression, Stress, Anxiety, and Anger of Females in Substance Abuse Rehabilitation. Journal of Music Therapy, 200542 (1), 64-80; doi: 10.1093/jmt/42.1.64

[7] P. Blackburn, H. M. Wikins, and B. Wiese. Depression in Older Adults: Diagnosis and Management, BCMJ, 2017 Vol. 59 , No. 3.

[8] A. AChan, O. Mok and B. Tse. A comparison of Singing, Vibrotactile, and non-vibrotactile instrumental playing responses in severely regressed persons with dementia of the Alzheimer's type. Journal of Music Therapy, 2009. 27, 119125. 
[9] L. Costa. Interpersonal Psychotherapy for Depression and Other Disorders in D. Barlow (Ed.), Clinical Handbook of Psychological Disorders 309-331. 1991. New York, NY: The Guilford Press.

[10] P. Dines, W. H. and C. Sajatovic. Depression in Later Life: An Overview of Assessment and Management. Psychiatria Danubina. 2014 Vol. 26, Supp 1, pp 78-84. Zagreb Croatia.

[11] C. A. Ekeopara and A. M. Ugoha. The Contributions of African Traditional Medicine to Nigeria's Health Care Delivery System. IOSR Journal of Humanities and Social Science (IOSR-JHSS) 2001. Volume 22, Issue 5. P. 32-43.

[12] R. Evans and A. Cox. The Use of Music Therapy and Activities with Demented Patients who are Deemed Difficult to Manage." Special: The Elderly Uncooperative Patient. Clinical Gerontologist, 1997. Vol. 62, 131-144.

[13] L. Fanous and A. Gardner. Neuroticism and Major Depression in Late Life: A Population Based Twin Study. Social Indicators Research, 2012. Vol. 40, 285-298.

[14] C. Frazer, H. Christenssen and K. M. Griffiths. Effectiveness of Treatments for Depression in Older people. Medical Journal. 2001. Vol. 13: 127-138.

[15] O. Gureje, L. Kola \& E. Afolabi. Epidemiology of Major Depressive Disorder in Elderly Nigerians in the Ibadan Study of Ageing: A community-based survey. Lancet 2007. 370: 957-64.

[16] M. Hamilton. Development of a Rating Scale for Primary Depressive Illness. British Journal of Social and Clinical Psychology 1967. Vol. 6: 278-96.

[17] W. Han, A. Kwan, Chen., O. Yusof, K. Chonh, O. Goh and H. Yap. Effects of Music on Major Depression in Psychiatric Patients. Archives of Psychiatric Nursing, 2010. Vol. 18, 193199.

[18] S. B. Hanser. The New Music Therapist's Handbook (2nd ed.). Boston, MA: 2013. Berklee Press.

[19] B. Heady and A. Wearing Personality, Life Event and Subjective. Well-Being; Toward a Dynamic Equilibrium Model. Journal of Personality and Social Psychology. 2009. Vol. 57, 731-739.

[20] O. Idowu, O. Yusuf, O. Akpa, and O. Gureje. A Random Effect of Logistic Regression Model of Major Depressive Disorder among Ageing Nigerians. American Journal of Mathematis and Statistics 2017. Vol. 62: 71-78.

[21] O. John, E. Donahue and R. Kentle. The "Big Five" Inventory Versions 4c and 54. Berkeley. University of California Berkeley Institute of Personality and Social Research 1991.

[22] H. L. Lai and M. Good. Music Improves Sleep Quality in Older Adults. Journal of Advance Nursing 2005 Vol. 49, 234 244.

[23] J. Madineh, A. Sanaz and F. Roghareli. The Effects of Music Therapy on Anxiety and Depression of Cancer Patients Indian Journal of Palliative Care, 2016. Vol. 22. 112-120.

[24] A. Morse and Lynch. Exploring the Influence of Personality on Depressive Symptoms and Self Esteem across a Significant Life Transition. Journal of Personality and Social Psychology. 2004. Vol. 85, 922-932. Memorial Fund Quarterly. Health and Society.
[25] National Council on Aging 2016. Falls Prevention: Fact Sheet. Retrieved from http://www.ncoa.org/view/resources-forreporters

[26] National Population Commission (NPC) and ICF International. Nigerian Demographic and Health Survey, 2013. Abuja, Nigeria and Rockville, Maryland, USA and ICF International.

[27] O. M. Osimade. Effectiveness of Laughter Therapy and Music Intervention in the Psychological Management of Geriatric Depression among Rural Community Dwelling Older Adults in Oyo State, Southwest Nigeria. Journal of Psychology and Psychotherapy, 2020 Vol 10. Iss 4 No. 376.

[28] R. Palmer. The Science of Laughter. Psychology Today, 2010. Vol. 33, 58-63.

[29] A. Richard, G. Jenkins and G. B. Thomas. Health Locus of Control, Chemotherapy-related Distress, and Response to Behavioural Interventions in Cancer Patients. Psychology and Health, 2013. Vol. 10, 463-475.

[30] T. T. Salami. Chronological Definitions and Expectations of Old Age among Young Adults in Nigeria. Journal of Aging Studies. 2010 Vol. 1: 113-124.

[31] T. Salami. Expression and the Nature of Emotion. Approaches to Emotion, 1999. Vol. 3, 19-344.

[32] A, Shah and R. Harris. Growing Old in Modern Society. Charles C. Thomas Publishers Ltd. Springfield. Illionis 2013. USA.

[33] P. Strauss and L. Solomon. Screenings for Depression Across the Lifespan: A Review of Measures for Use in Primary Care Settings. American Family Physician, 2010 Vol. 66, 6.

[34] P. L. Tanyi, P. Andre and P. Mbah. Care of the Elderly in Nigeria: Implications for policy. Cogent Social Sciences, 2018. 4: 1, 1555201 DOI https://doi.org/1080/23311886

[35] United Nations. World Population Ageing 2015.

[36] S. Unutzer, W. Katon. Collaborative Management of Late Life Depression in the Primary Care Settings: A Randomized Controlled Trial, JAMA. 2013. Vol. 12: 2836-2845.

[37] N. N Umeaku, O. N. Harry and C. C. Anolue. Assessing the Effectiveness of Cognitive Behavioural Therapy on Depressive Symptoms among Polycystic Ovary Syndrome Patients Receiving Fertility Treatment International Journal of Research and Innovation in Social Science (IJRISS). 2020. Vol. IV, Issue 1, ISSN 2454-6186.

[38] B. S. Wallston, K. A. Wallston, G. D. Kaplan and S. A. Maides. 1970. Development of and Validation of the Health Locus of Control Scale. Journal of Counseling and Clinical Psychology, Vol. 44 (4), 580-585.

[39] WHO 2017. Depression and other common mental disorders: Global Health Estimates. World Health Organization, Geneva2. Available at http://www.who.international/mental_health/management/dep ression

[40] J. Yesavage, T. Brink, T. Rose, O. Lum, V.Huang, M. Adey and V. Leirer. Development and Validation of a Geriatric Depression Screening Scale: A Preliminary Report. Journal of Psychiatric Research, 1983. 17, 37-49.

[41] A. Zimmerman, 2011. Ethnic Variation in Depressive Symptoms in Community Sample. Cultural Diversity and Ethnic Minority Psychology. 13 (1), 35-44. 
[42] N. Gaines, 2020. Music Therapy Techniques, Exercises and Outcomes. Article published at http://www.regainus. Accessed: August, 2020).

[43] P. Costa and R. McCrae, R. 1992 Revised NEO Personality Inventory (NEO-Pi R) and NEO Five Factor Inventory (NEOFFI) Professional Manual Odessa, FI: Psychological Assessment Resources Inc.
[44] L. Golberg, 1993. An Alternative "Description of Personality": The Big-Five Factor Structure Journal of Social and Clinical Psychology, Vol. 6: 278-96.

[45] D. P Crown and D. Marlowe. 1964. The Approval Motive. New York: Wiley. 